\title{
A Novel Method For The Provision Of Flight Experience And Flight Testing For Undergraduate Aeronautical Engineers At The University Of Strathclyde
}

M T Stickland and T J Scanlon, Department of Mechanical Engineering, University of Strathclyde

\begin{abstract}
The Department of Mechanical Engineering at the University of Strathclyde has developed a novel flight experience/test course for undergraduate Aeronautical Engineers. In common with similar courses at undergraduate level the course contains practical instruction in how an aircraft is flown, an analysis of its stall characteristics and an assessment of an aircraft's performance and stability. However, uniquely, the Strathclyde course consists of dual instructional flights in two seat gliders. This paper contains a detailed description of the flight experience/test course developed at Strathclyde and its incorporation into the undergraduate curriculum . A critical analysis of its delivery is also presented.
\end{abstract}




\section{Nomenclature}

$\begin{array}{ll}k & \begin{array}{l}\text { Induced drag factor } \\ g\end{array} \\ \alpha & \text { acceleration due to gravity } \\ C_{L} & \text { lift coefficient } \\ C_{D} & \text { drag coefficient } \\ C_{D o} & \text { lift independent (parasite) drag coefficient } \\ \text { kts } & \text { knots (nautical miles per hour) } \\ \text { mac } & \text { mean aerodynamic chord }\end{array}$

\section{Introduction}

The development of the Aero-Mechanical Engineering degree at the University of Strathclyde has been driven by the interest shown by undergraduates in this exciting field of engineering. In 1992 a B.Eng. in Mechanical Engineering with Aerodynamics was introduced. This "with" degree required the student to take two, final year, elective classes which covered flight mechanics, aerodynamics and aircraft propulsion systems. The large number of students taking these elective classes encouraged the authors to develop more aeronautical engineering classes so that, by 1996, the five year M.Eng. Mechanical Engineering with Aeronautics degree was introduced. This "with" degree required the students to take aeronautical related electives each year from their second onwards. The two "with" degrees were accredited by the Institute of Mechanical Engineers. Comparison of the "with Aero" degree with full Aeronautical Engineering degrees provided by other Universities showed there to be little if any 
difference in the overall course content and that, with only a small alteration of the syllabus, it would be possible to apply to the Royal Aeronautical Society for accreditation as an Aeronautical Engineering degree. In 2000 the AeroMechanical Engineering degree course was given provisional accreditation by both the RAeS and the IMechE. The Accreditation by the RAeS was, however, conditional on the provision of some form of flight experience and flight test within the syllabus. It was noted that, whilst this is not a mandatory requirement ${ }^{[1]}$, it is regarded by the accreditation committee as a highly desirable part of an undergraduate degree. The following paper discusses the development of a flight test/experience course to satisfy this requirement.

\section{UK provision of flight experience/test}

Ransom et $\mathrm{al}^{[2]}$ state that there are currently thirty universities in the UK providing some form of Aerospace Engineering education. The contents of these courses are not exactly the same and the variations in content are echoed in the choice of course names; Aerospace Engineering, Aeronautical Engineering, Aeromechanical Systems Engineering, Aerospace Technology with management etc. The courses, accredited by the Royal Aeronautical Society, require their students to gain actual flight experience and undertake some form of flight test. A survey of the accredited courses provision of flight experience/test may be found in table 1.

\begin{tabular}{|l|l|}
\hline Cranfield National flying laboratory & 16 \\
\hline Other & 4 \\
\hline
\end{tabular}

Table 1 - Provision of flight test/experience 
It may be seen that the majority of the courses offering flight test use a flight test/experience course provided by Cranfield University. However, it was noted that departments are now beginning to incorporate flight simulation into their courses and, due to the financial implications, are replacing some of their flight test requirement by time on a simulator. The RAeS recognises this and allows the use of simulators in the provision of flight test/experience. However, whilst simulation is a useful addition to an undergraduate degree the authors still considered that actual flight experience should be provided.

\subsection{Strathclyde flight test course}

Although Strathclyde has been teaching Aeronautical Engineering over the past ten years, the Aero-Mechanical degree at Strathclyde was only introduced in the academic year 2001/2002. The newness of the degree allowed the authors to consider, in the light of what other Universities provide, the way flight experience/test could be introduced to the course. Initially it was considered that provision of flight experience utilising light aircraft, in a similar way to the University of Bath, might be feasible. However, the high cost was prohibitive. Therefore, either Strathclyde would need to use the services of the University of Cranfield or a novel approach was required.

The University of Strathclyde is extremely active in the ERASMUS and SOCRATES schemes and has exchanged many students with universities in Germany. During these exchanges the authors' attentions have been drawn to the excellent work carried out by the AKAFliegs, (Academic Flying groups $)^{[3]}$. These groups are voluntary and membership is not a prerequisite 
of the German Aeronautical Engineering degrees. However their influence may been seen in the fact that the Sailplane Manufacture industry in Germany is the world leader with $90 \%$ of the sailplanes designed and built there ${ }^{[3]}$. They also provide a focus for undergraduate and postgraduate project work. The success of the AKAFliegs and the possibility that the simplicity of a sailplane would lend itself to analysis made the development of a course based around sailplanes an attractive proposition.

To this end the Scottish Gliding Centre at Portmoak was approached to see if they would be amenable in assisting with the development of a flight test course based around a series of flights in two seat training gliders. They agreed to participate and a syllabus was developed.

The Syllabus is loosely based around the types of testing undertaken in the Cranfield Jetstream. However, the available flight instrumentation limited the test possibilities. But even with these limitations a comprehensive course was developed.

\subsection{Class syllabus}

The flight experience/test course is integrated into a second year class, Aero Design 1. The aim of this class is to introduce students to the process by which an aircraft is designed. The syllabus contains: 
- The design process. (project definition, design teams, CAD, concurrent engineering.)

- Airworthiness and the flight envelope (JAR22)

- Performance (steady level flight - stall, min. drag and min. power speeds, steady glide and climb, take-off and landing, steady turning flight, range and endurance.

- Longitudinal static stability and control.

- Data sheets (ESDU)

- Flight experience/test.

The class takes, as its core, the design of a two seat glider, the Schleicher ASK21. During the discussion of airworthiness requirements the flight envelope of the ASK21 is determined from JAR22. Courseworks on performance calculations are also based on the ASK21 and include:

- Calculation of $\mathrm{C}_{\mathrm{Do}}, \mathrm{k}$, stall speeds, IAS for max range, minimum glide angle, minimum sink rate, IAS for minimum sink rate, effect of airbrakes.

- Calculation of the neutral point and static margin stick fixed.

The calculations for takeoff and landing, range and endurance are based around a heavy lift model aircraft as the students are required to take part in the British Model Flying Association "University Challenge" in their third year. The BMFA competition is incorporated into the students' third year design class and requires the students to design, build and fly a remote controlled 
aircraft. The specification for the aircraft is contained in the rules of the BMFA competition. More information on this competition may be found on the authors' web site ${ }^{[4]}$.

By the end of the taught part of the curriculum in early May the students are prepared for participation in the flight experience/test course.

The flight experience/test course is residential over three days and is based around four flights per student in ASK21 two seat gliders. There are five students present on each course. All flights are via aero tow to 4000 feet if the cloud base permits, figure 1.

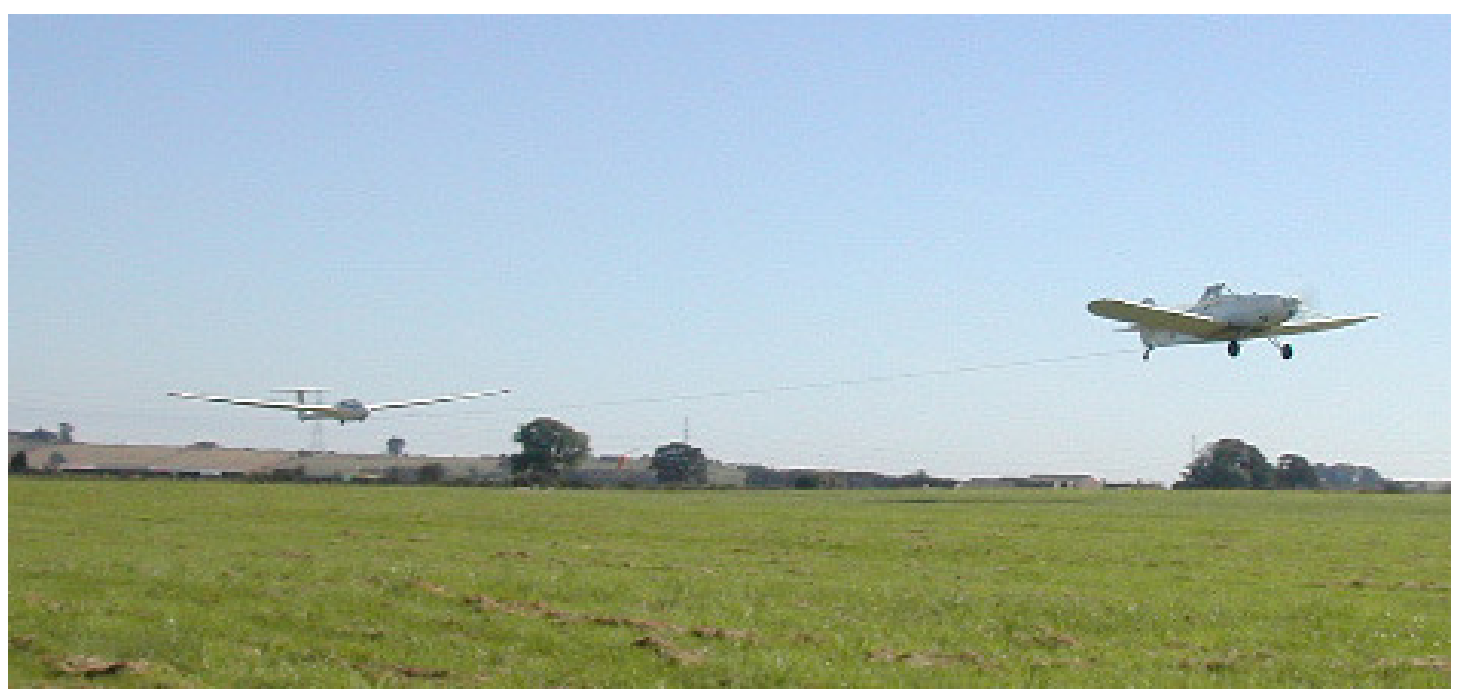

Figure 1: glider taking off on aero tow.

At the start of the course the students attend a safety briefing where they are informed of general safety on an airfield and the particular hazards when launching aircraft via winch or aero tow. They are also given basic instruction in aircraft handling. The students are then taken to the aircraft where they are 
given further instruction in: fitting of parachute, use of Parachute, harness and quick release, flight Instruments and flight controls. They also check their weight against the cockpit placard limits. The students are then given a briefing for the first flight. It should be noted that all flying is dual and carried out with a British Gliding Association qualified instructor.

\subsubsection{Flight 1: Demonstration of aircraft controls}

The purpose of the first flight is to demonstrate the aircraft controls and instruments to the students and get them used to flying the aircraft before the more rigorous exercises later in the course. The effects of deflecting the rudder, elevator, ailerons and trimmer are demonstrated and then the students are allowed to fly the aircraft, attempting to control heading, airspeed and co-ordinate turns. They are also introduced to the effect of reducing the airspeed too much - the stall. Each flight lasts about 30 minutes.

\subsubsection{Flight 2: The stall}

The second flight's purpose is to investigate the stall and stall recovery,

Prior to the flight the students have calculated the gross mass of their aircraft and, given the wing area from the aircraft handbook and the $C_{L}-v s-\alpha$ plots for the wing sections, calculate the indicated airspeed (IAS) for the stall of the aircraft in straight and level flight and in a $2 \mathrm{~g}$ turn.

During the flight the stall is demonstrated by the instructor. The "Mushing" stall is investigated in which the aircraft speed is allowed to reduce gradually and 
the indications of the stall - buffet, increased rate of sink, reduction in aileron effectiveness and decrease in wind noise are demonstrated. The changing effect of the rudder as the stall is approached (as the rudder is deflected the aircraft rolls) is demonstrated. The possibility of a wing dropping at the stall, creating the possibility of a spin, is also shown. Steep stall from level flight is investigated in which the aircraft is pulled into a steep climb and the speed allowed to decay. When the aircraft now stalls the low airspeed causes the tail plane and elevator to lose their effectiveness and the nose drops. As the nose drops the elevator is still ineffective and this is demonstrated. To demonstrate that the aircraft can stall at any speed the aircraft is established in a $2 \mathrm{~g}, 60^{\circ}$, banked turn and the speed reduced until the stall is approached. If time permits, the student is allowed to stall the aircraft in level flight. The indicated air speed (IAS) at which the aircraft stalled in level flight and the airspeed at which the aircraft stalled in the $2 \mathrm{~g}$ turn are recorded. If the load factor was not exactly 2 during the accelerated stall, the student records the actual $\mathrm{g}$ for post flight analysis.

Post flight the estimated stall speeds from the courseworks are compared with the actual values from the flight and the results discussed.

\subsubsection{Flight 3 - performance and static stability}

The third flight's purpose is to compare a theoretical analysis of the aircraft's performance and static stability stick fixed with actual flight data. 
Prior to the flight the students have calculated the drag coefficient of the aircraft;

$$
C_{D}=C_{D_{o}}+k C_{L}^{2}
$$

where $C_{D_{o}}$ is the parasite drag and $\mathrm{k}$ is the induced drag factor, working from very limited information and using analytical and empirical equations and ESDU data sheets. Also calculated in course works: the drag coefficient for the aircraft with full airbrake deployment, the IAS for minimum sink rate (max endurance), the minimum sink rate, the IAS for minimum glide angle (max range) and the sink rate at 50kts with full airbrake, the theoretical location of the neutral point, stick fixed, of the aircraft and the static margin are determined. A calibration of control column position against elevator deflection is made.

During the test flight the aircraft is flown at a number of constant airspeeds with and without airbrakes deployed. At these airspeeds the IAS and the time to descend 100 feet are recorded. For the measurement points without airbrake the distance of the control column from a fixed point on the instrument panel is also recorded. The time to descend 100 feet at $50 \mathrm{kts}$ with full airbrake deployed is recorded. The aircraft speed is reduced gradually and the speed at which the minimum sink rate, as shown on the vertical speed indicator, occurs is recorded. 
Post flight $C_{D_{o}}$ and $\mathrm{k}$ for both the clean aircraft and with airbrakes deployed are calculated from the flight test data. A similar analysis is undertaken from the data presented in the manufacturer's polar curve for the clean aircraft. The theoretical, flight test and manufacturers drag coefficient data for the clean aircraft are compared and discussed. The minimum sink rate and IAS for min sink rate are compared with the calculated values. The increment in the aircraft drag caused by the airbrake deflection is compared with the value calculated from ESDU datasheets.

\subsubsection{Flight 4: Static and Dynamic Stability,}

Prior to the flight the students have discussed qualitatively the phugoid and spiral divergence of an aircraft

During the flight the short period oscillation, the spiral divergence, and the phugoid oscillation are demonstrated. The aircraft is then flown in four phugoid oscillations with initial conditions of $60 \mathrm{kts}$ IAS, $10^{\circ}$ and $30^{\circ}$ pitch angle, stick fixed and stick free. During each phugoid the student records the maximum and minimum IAS and makes a subjective assessment of whether or not the oscillation is damped.

The data recorded during the flight are retained for use in a third year class "Flight and Space Flight 2" when the equations of motion of an aircraft are derived, flight simulation and dynamic stability are introduced. The data recorded on this flight are then compared to the theoretical models derived. 
At the end of each flight, after the required data have been acquired, the student is allowed to fly the aircraft for as long as possible. At the end of the fourth flight the students usually ask the instructor to demonstrate some aerobatic manoeuvres which the instructors do with great enthusiasm.

\section{Discussion}

\subsection{General overview}

A trial of the flight test course was undertaken in September 2002 and the first course for second year students was run in May 2003. The course met, if not surpassed, all expectations. The students found the course to be an educational experience as well as a lot of fun. The flying and theoretical work complemented each other and reinforced the students' knowledge of flight mechanics and aerodynamics

\subsection{Flight data}

\subsubsection{The stall}

The calculations produced a result within $1 \mathrm{kt}$ (typically $37 \mathrm{kts}$ ) of the stall speed for the aircraft in level flight and within about $5 \mathrm{kts}$ of the measured stall in the $2 g$ turn. Post flight the students recalculated the accelerated stall speed for the actual $g$ they pulled and got a better correlation. 


\subsubsection{Performance}

The data produced by the flight test usually agrees well with the theoretical values and the manufacturer's own data. However, the accuracy of the results does rely on atmospheric conditions during the test as the calm conditions required are not always available at low altitude. However, disagreement between the data does cause an interesting discussion into the cause.

\subsubsection{Static Stability}

The calculation of the neutral point by flight test requires airspeed and elevator deflection data to be recorded with the centre of gravity of the aircraft at a number of different positions. The movement of the centre of gravity in the K21 is dependent upon the different masses of the students in the front seat. Therefore the range of movement is limited to approximately $5 \%$ mac.

\subsection{Course development}

Analysis of the data generated and the performance of the students during the flights highlighted several areas where the course could benefit from refinement.

\subsubsection{Flight data}

The instruments used were the standard flight instruments within the aircraft and their state of calibration was unknown. The vertical speed indicator (VSI) is not a very accurate instrument to determine rate of sink and its data can 
only be taken as approximate values. However, the benefits of the immediacy of the data presented by the VSI should not be overlooked. Recording the time to decent $100 \mathrm{ft}$ was the most accurate method available although rate of decent could only be determined post-flight.

\subsubsection{Course Structure}

The theoretical work carried out in the class integrated well with the practical work of the flight course and reinforces the learning objectives. The time available on site was limited and it was therefore essential that all theoretical work was carried out before the flight course took place and was better utilised for post rather than pre flight analysis. The performance measurements became rather repetitive as the same aircraft configuration was tested many times. In the future a different glider, DG505, would be preferable. The DG505 has removable wing tips which would allow the aspect ratio can be varied and the effect of aspect ratio on induced drag to be investigated. It has a retractable undercarriage which would allow a comparison of ESDU data for undercarriages as well as airbrakes to be undertaken. Also the variable centre of gravity in the DG505 (by loading water ballast in the fin) could be used to give a wider centre of gravity range for the static and dynamic stability flights.

\subsubsection{Costs}

The costs of the course are not unreasonable, approximately $£ 200$ per person, and estimated to be the same as the expenditure by other aeronautical departments. 


\subsubsection{Possible difficulties}

We rely on the good will of the Scottish Gliding Centre to provide instructors and tug pilots. As student numbers become large this may create difficulties. However, the benefit to the club of the large income stream it will produce may preclude this.

\section{Conclusion}

A novel flight experience/test course has been developed which is based around four flights in a two seat glider. Whilst the flight instrumentation in the aircraft is limited a comprehensive syllabus has been developed. However, the simplicity of the instrumentation and test flight profiles adopted allows the students to fly some of the tests themselves. Students, who have participated on the course confirm that there are significant benefits in allowing the student to become intimately involved with the test flights.

\section{References}

1. Route to Registration as a Chartered Engineer Via The Royal Aeronautical Society. Paper from the Professional Affairs Board of the Royal Aeronautical Society $21^{\text {st }}$ June 1995

2. Ransom E, Self A. The Origins of Aerospace Engineering Degree Courses. Aircraft Engineering and Aerospace Technology, Vol. 74, No 4, 2002 pp 355-364 
3. Association of German Academic Flying Groups http://www.idaflieg.de/english/index.html

4. BMFA University Challenge

http://homepages.strath.ac.uk/ clcs20/bmfa1999.htm 